\title{
On the verge of using an immune toolbox in the intensive care unit?
}

\author{
Frédéric Pène ${ }^{1^{*}} \mathbb{D}$, Jean-Louis Vincent ${ }^{2}$ and Ignacio Martin-Loeches ${ }^{3}$
}

(c) 2017 Springer-Verlag Berlin Heidelberg and ESICM

Thanks to earlier recognition of sepsis and advances in its management, most patients with septic shock now survive the early phase of resuscitation, although there remains a high risk of death as a result of a protracted inflammatory response and/or increased susceptibility to secondary complications [1]. Beyond the classical and undisputed endpoint of mortality, intensive care unit (ICU)-acquired infections (IAI) are of real concern [2]. The risk of developing IAI is influenced by multiple clinical factors, including underlying comorbidities, initial severity of sepsis and need for invasive procedures, but these factors do not fully account for the individual risk of IAI.

A number of experimental and clinical studies have indicated that acquired immune suppression largely contributes to the pathophysiology of secondary infections [3]. This concept has emerged at a time when the clinical critical care community has been disappointed with the results of multiple trials of anti-inflammatory sepsis therapies. In addition, while prompt broad-spectrum antimicrobial therapy has been associated with better outcomes at the most severe end of the sepsis spectrum, timely antimicrobial de-escalation, based on microbiologic identification, susceptibility testing and clinical improvement, is an essential strategy to conserve the effectiveness of existing antimicrobials and prevent the emergence of resistance [4]. Clearly, novel approaches to the diagnosis and clinical management of nosocomial infections are urgently needed.

With the demonstration that sepsis and other acute inflammatory conditions can promote a complex immunosuppressive status, several biomarkers have been

\footnotetext{
*Correspondence: frederic.pene@aphp.fr

${ }^{1}$ Medical ICU, Cochin Hospital, Assistance Publique-Hôpitaux de Paris and University Paris Descartes, Paris, France

Full author information is available at the end of the article
}

investigated for their ability to predict mortality or the development of nosocomial infections (Fig. 1). Deactivation of monocytes, as assessed by a low expression of the antigen presentation apparatus [human leukocyte antigen-antigen D related (HLA-DR) test], is viewed as the most relevant marker of acquired immune suppression and has been linked to increased mortality as well as increased susceptibility to IAI $[5,6]$. The pitfalls of HLA-DR measurement include the need for immediate cell staining with fluorescent antibodies and for a flow cytometer and a skilled technician. Although automated point-of-care systems are being developed, the ability to monitor HLA-DR expression currently remains largely restricted to working hours. Lymphopenia has also been considered to be predictive of IAI, although the differential behavior of lymphocyte subsets makes it difficult to interpret the results [7-9]. Recently, whole-genome transcriptome analysis has added a new layer of complexity to the understanding of immune regulation in this setting $[2,10,11]$.

Peronnet and colleagues addressed the performance of alternative molecular biomarkers to predict IAI [12]. Using quantitative real-time PCR, these authors assessed the systemic expression of the prototypic anti-inflammatory cytokine interleukin (IL)-10 and of the CD74 invariant chain involved in the formation and transport of major histocompatibility complex class II proteins and, therefore, a surrogate marker for cell surface HLA-DR expression. They studied 19 healthy volunteers to assess steady-state gene expression and 725 non-immunocompromised patients, including $70 \%$ with an infection and $50 \%$ with septic shock. The cumulative incidence of IAI was $19 \%$, occurring at a median of 10 days following ICU admission. Sequential whole blood samples were obtained at the time of ICU admission (day 1) and on days 3 and 6 . IAI occurred more frequently in patients with a decrease in CD74 mRNA expression between day 


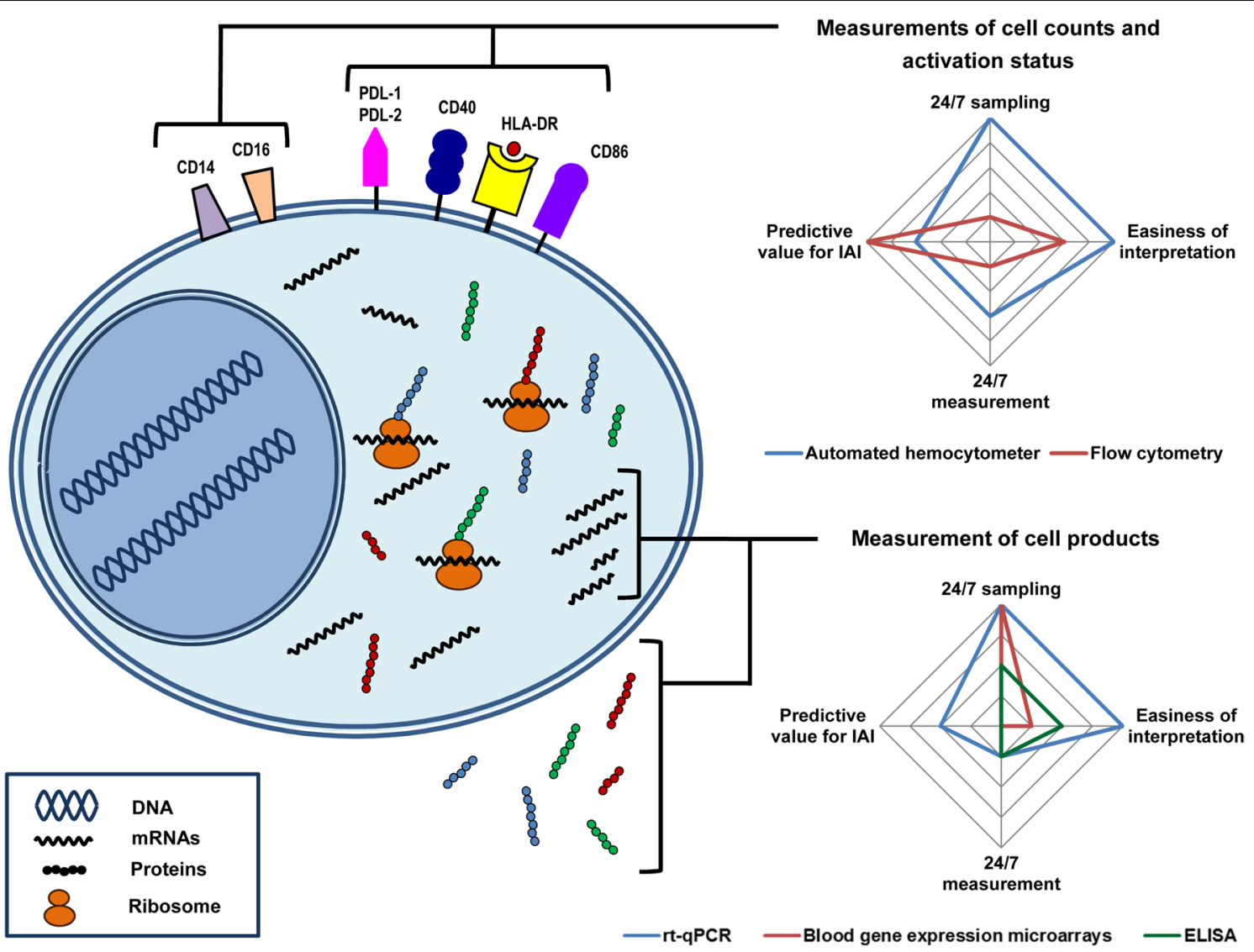

Fig. 1 Phenotyping immune cells in critically ill patients. Acute inflammatory disorders induce quantitative changes and functional defects in immune cells. Cells can be counted by an automated hemocytometer depending on their size and granulometry. Flow cytometry enables refinement of the distribution of cell subsets through the expression of surface differentiation markers (e.g., CD14 and CD16 for monocytes) and assessment of their activation status (e.g., expression of the antigen presentation apparatus with the HLA-DR test). Cell products include mRNA and their resulting proteins. mRNA expression can be quantified at the single- and whole-genome levels through reverse-transcriptase quantitative polymerase chain reaction $(r t-q P C R)$ and microarrays, respectively. Protein products can be quantified by enzyme-linked immunosorbent assays (ELISA). The advantages and drawbacks of these methods are displayed on the radar graphs with respect to their convenience in the intensive care setting (24/7 sampling and centralized or point-of-care measurements), ease of interpretation and current performance for the prediction of infections acquired in the intensive care unit (IAI)

1 and day 3 and in patients with higher levels of IL-10 mRNA on day 3 . Of note, lymphocyte counts remained similar at all time points in patients with IAI and in those without.

The study has several strengths, including the size of the cohort, which is much larger than usual for this type of investigation, and the statistical analysis, which took into account the competing risks of IAI, such as death and discharge alive from the ICU, and adjusted for some potential confounders at ICU admission, such as sepsis and shock. The time interval between samples and onset of IAI makes it unlikely that the immune dysfunction on day 3 was caused or worsened by the secondary infectious insult, which generally occurred later on. Nonetheless, some limitations have to be highlighted. First, the control subjects were blood donors, and were generally much younger than the patients. The impact of ageing on immune function, the so-called immunosenescence, has rarely been taken into account in such translational studies [8]. Second, CD74 mRNA expression was correlated to HLA-DR measurements by flow cytometry in only a small subset of patients. Most importantly, the study only included a discovery cohort, without a validation cohort.

The major question is how can the results from such exploratory studies be translated to effective clinical application of immunomonitoring for the diagnosis and/ or treatment of nosocomial infections? We now have relevant biomarkers to address the immune status of critically ill patients. The collection of RNA is convenient and adapted to the clinical 24/7 ICU setting, although the 
subsequent steps to gene expression measurements need to be carried out rapidly if they are to be included in a decision-making process. How these molecular tools may actually impact on clinical management remains elusive. Some immune defects are amenable to immune-enhancing therapeutics, and several biomarker-based therapeutic interventions have thus been proposed to prevent or treat IAI, including granulocyte-macrophage colonystimulating factor and interferon-gamma to reverse monocyte deactivation, IL-7 to stimulate lymphocyte proliferation and anti-checkpoint molecules to restore lymphocyte activation [13-15]. Furthermore, stratifying the risk of IAI has become essential in modern critical care medicine because the commonly used diagnostic criteria for infection have limited sensitivity and specificity in the ICU and may result in delayed or excessive antibiotic prescription. The study of Peronnet and colleagues [12] suggests that immune profiling of critically ill patients could be integrated into a multimodal realtime diagnostic work-up of IAI in the near future. This would represent an important step towards more personalized medicine in the ICU.

\begin{abstract}
Author details
${ }^{1}$ Medical ICU, Cochin Hospital, Assistance Publique-Hôpitaux de Paris and University Paris Descartes, Paris, France. ${ }^{2}$ Department of Intensive Care, Erasme University Hospital, Université libre de Bruxelles, Brussels, Belgium. ${ }^{3}$ Multidisciplinary Intensive Care Research Organization (MICRO), St. James's Hospital DublinTrinity Centre for Health SciencesTrinity College (TCD), Irish Centre of Vascular Biology (ICVB), Dublin, Ireland.
\end{abstract}

\section{Compliance with ethical standards}

\section{Conflicts of interest}

FP, JLV and IML have no competing interests related to the present manuscript.

Received: 2 May 2017 Accepted: 6 May 2017

Published online: 11 May 2017

\section{References}

1. Daviaud F, Grimaldi D, Dechartres A, Charpentier J, Geri G, Marin N, Chiche JD, Cariou A, Mira JP, Pène F (2015) Timing and causes of death in septic shock. Ann Intensive Care 5:16

2. van Vught LA, Klein Klouwenberg PM, Spitoni C, Scicluna BP, Wiewel MA, Horn J, Schultz MJ, Nurnberg P, Bonten MJ, Cremer OL, van der Poll $\mathrm{T}$ (2016) Incidence, risk factors, and attributable mortality of secondary infections in the intensive care unit after admission for sepsis. JAMA 315:1469-1479
3. Hotchkiss RS, Monneret G, Payen D (2013) Sepsis-induced immunosuppression: from cellular dysfunctions to immunotherapy. Nat Rev Immunol 13:862-874

4. Zilahi G, Artigas A, Martin-Loeches I (2016) What's new in multidrugresistant pathogens in the ICU? Ann Intensive Care 6:96

5. Monneret G, Lepape A, Voirin N, Bohe J, Venet F, Debard AL, Thizy H, Bienvenu J, Gueyffier F, Vanhems P (2006) Persisting low monocyte human leukocyte antigen-DR expression predicts mortality in septic shock. Intensive Care Med 32:1175-1183

6. Landelle C, Lepape A, Voirin N, Tognet E, Venet F, Bohe J, Vanhems P, Monneret $G$ (2010) Low monocyte human leukocyte antigen-DR is independently associated with nosocomial infections after septic shock. Intensive Care Med 36:1859-1866

7. Drewry AM, Samra N, Skrupky LP, Fuller BM, Compton SM, Hotchkiss RS (2014) Persistent lymphopenia after diagnosis of sepsis predicts mortality. Shock 42:383-391

8. Grimaldi D, Le Bourhis L, Sauneuf B, Dechartres A, Rousseau C, Ouaaz F, Milder M, Louis D, Chiche JD, Mira JP, Lantz O, Pène F (2014) Specific MAIT cell behaviour among innate-like T lymphocytes in critically ill patients with severe infections. Intensive Care Med 40:192-201

9. Adrie C, Lugosi M, Sonneville R, Souweine B, Ruckly S, Cartier JC, Garrouste-Orgeas M, Schwebel C, Timsit JF (2017) Persistent lymphopenia is a risk factor for ICU-acquired infections and for death in ICU patients with sustained hypotension at admission. Ann Intensive Care 7:30

10. Shalova IN, Lim JY, Chittezhath M, Zinkernagel AS, Beasley F, HernandezJimenez E, Toledano V, Cubillos-Zapata C, Rapisarda A, Chen J, Duan K, Yang H, Poidinger M, Melillo G, Nizet V, Arnalich F, Lopez-Collazo E, Biswas SK (2015) Human monocytes undergo functional re-programming during sepsis mediated by hypoxia-inducible factor-1alpha. Immunity 42:484-498

11. Davenport EE, Burnham $\mathrm{KL}$, Radhakrishnan J, Humburg $\mathrm{P}$, Hutton $\mathrm{P}$, Mills TC, Rautanen A, Gordon AC, Garrard C, Hill AV, Hinds CJ, Knight JC (2016) Genomic landscape of the individual host response and outcomes in sepsis: a prospective cohort study. Lancet Respir Med 4:259-271

12. Peronnet $E$, Venet $F$, Maucort-Boulch D, Friggeri A, Cour M, Argaud L, Allaouchiche B, Floccard B, Aubrun F, Rimmelé T, Thiolliere F, Piriou V, Bohé J, Cazalis M, Barbalat V, Monneret G, Morisset S, Textoris J, Vallin H, Pachot A, Lepape A (2017) Association between mRNA expression of CD74 and IL 10 and risk of ICU-acquired infections. A multicenter cohort study. Intensive Care Med. doi:10.1007/s00134-017-4805-1

13. Meisel C, Schefold JC, Pschowski R, Baumann T, Hetzger K, Gregor J, Weber-Carstens S, Hasper D, Keh D, Zuckermann H, Reinke P, Volk HD (2009) Granulocyte-macrophage colony-stimulating factor to reverse sepsis-associated immunosuppression: a double-blind, randomized, placebo-controlled multicenter trial. Am J Respir Crit Care Med 180:640-648

14. Grimaldi D, Pradier O, Hotchkiss RS, Vincent JL (2017) Nivolumab plus interferon-gamma in the treatment of intractable mucormycosis. Lancet Infect Dis 17:18

15. Venet F, Foray AP, Villars-Mechin A, Malcus C, Poitevin-Later F, Lepape A, Monneret G (2012) IL-7 restores lymphocyte functions in septic patients. J Immunol 189:5073-5081 